\title{
Towards Community Collections Management
}

\author{
Vincent Stuart Smith ${ }^{\ddagger}$, Steen Dupont ${ }^{\ddagger}$, Matt Woodburn ${ }^{\ddagger}$ \\ ‡ The Natural History Museum, London, United Kingdom
}

Corresponding author: Vincent Stuart Smith (vince@vsmith.info)

Received: 05 Oct 2020 | Published: 09 Oct 2020

Citation: Smith VS, Dupont S, Woodburn M (2020) Towards Community Collections Management. Biodiversity Information Science and Standards 4: e59341. https://doi.org/10.3897/biss.4.59341

\begin{abstract}
Collections Management Systems (CMS) are central to the operation of many natural science collections. Over the past few decades, these have evolved from simple tables and databases recording the contents of our collections, to take on multiple roles supporting complex business processes and information management needs within our organisations. These new functional demands have often outpaced the technical development of these systems and organisational capacity to sustain them. Furthermore, their contents essentially remain institutional silos, managed and controlled by single institutions, despite servicing data and a scientific mission that is shared across the global community.

The Natural History Museum, London (NHM) has recently embarked on a journey, working with peer institutions and external consultants, to develop a platform-agnostic set of requirements for a sustainable, scalable and interoperable CMS. The vision of a highly efficient, more flexible and connected solution that can engage with other collections-based organisations and stakeholders is not unique to the NHM, and working with others, including the developers of other CMS, we seek to generate a better understanding of shared collection management business processes, data and data models.
\end{abstract}

To achieve these goals, a dedicated year-long programme has been formed to address the many facets of a collections management system specification (requirements, processes, standards, models and compliance), and to engage the landscape of internal and external peers, stakeholders and CMS providers.

In this presentation, we will provide some background to explain how the NHM has arrived in its current position and discuss our vision for building on the discussion around existing 
standards, interoperability and data access. We will summarise the programme's structure and plans, report on the progress of the first few months, and highlight any challenges encountered and solutions delivered.

\section{Keywords}

Collection Management Systems (CMS), informatics, community, standards, database

\section{Presenting author}

Vincent Stuart Smith

\section{Presented at}

TDWG 2020

\section{Acknowledgements}

Presented on behalf of the RECODE (REthinking COllections Data Ecosystems) Board at the Natural History Museum, London. RECODE is the name of the Programme Board consisting of the following individuals who are leading this phase of the work to specify the requirements for a new Collections Management System at the Natural History Museum, London:

- $\quad$ Chris Jones (Chair), Head of Department, Core Research Labs

- $\quad$ Alison Davis, Chief Information Officer

- Sarah Long, Registrar

- $\quad$ Gerry Hey, Head, Collections Management Systems

- $\quad$ Mark Carine, Principal Curator in Charge, Algae, Fungi \& Plants

- Matt Woodburn, Science Data Architect

- $\quad$ Giles Miller, Principal Curator, Micropaleontology

- Ben Price, Senior Curator in Charge, small orders

- Helen Hardy, Digital Collections Programme Manager

- $\quad$ Vince Smith, Research Leader, Informatics

- $\quad$ Mike Sadka, Digital Information Systems Analyst

- Michael Loran, Digital Systems Librarian

- Steen Dupont, Digital Collections Project Manager 


\section{Author contributions}

Vincent Smith, Steen Dupont and Matt Woodburn co-wrote the abstract and prepared the presentation. The wider RECODE Board (see Acknowledgements) co-developed the CMS specification. 